\title{
Impairment of memory functions after acute head injury ${ }^{1}$
}

\author{
IRIS E. FODOR \\ From New York University, New York, N.Y. 10003, U.S.A.
}

SUMMARY When memory functions are evaluated after head injury, two trends are apparent Acute head injury patients with approximately normal intelligence demonstrate a reduced capacity to utilize structure in delayed recall relative to a control group. Furthermore, head injury patientso with low intelligence demonstrate a wider memory deficit than the previous group, affecting percep-ڤ tion and immediate recall as well. No relationship was found between severity of injury, recovery $\overrightarrow{0}$ and performance on the memory scale.

The period of post-traumatic amnesia (PTA) after head injury has been viewed as a measure of the impairment of consciousness, as well as an index of severity of injury (Schilder, 1934; Russell and Nathan, 1946; Smith, 1961). However, with closed head injury cases, relatively little research using objective test procedures to investigate general memory functioning during PTA has been conducted.

Comprehensive studies of memory functioning after head injury using both case histories and objective test procedures have been conducted (Schilder, 1934; Ruesch, 1944; Dailey, 1956; Chronholm and Jonsson, 1957), showing varied results. The research suggests that in the more confused state immediately after injury, perception of events is impaired. When the confusion clears, in the period corresponding to the PTA period, subjective reports of poor memory are still present. However, there is still a lack of information which would aid in more fully assessing whether the memory disturbance primarily involves retrieval or retention affecting short- and long-term memories.

In normal subjects, there is evidence to suggest separate memory mechanisms, one for shortterm and another for long-term memory. Furthermore, Talland (1960), Baddeley and War-

1 Submitted in partial fulfilment of the requirements of Doctor of Philosophy, Boston University, 1965. The research project was supported in part by the National Institute of Mental Health, grant number MPH-16, 464 rington (1970), and others find that short-term memory is intact, while long-term memory isw impaired in a mixed population of amnesic patients. It is also known that organization gipo stimulus material promotes retrieval by recolp (Norman, 1969). Thus, Buereger-Prinz and Kalia?

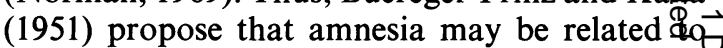
loose organizational ability. Talland (1960) ports that amnesic patients do no better whong given a highly structured recall task than wheng given a less structured one. The issue of amnegia as a deficit in organization has also been explorê, by Weiskrantz and Warrington (1971), who present evidence to dispute Talland's claim.

The aim of the present study is to study mem ory functioning in a head injury population singling out for special emphasis organizationaf ability and its relationship to perception and retrieval by immediate and delayed recall, aş well as recognition. The recovery of memory functions and the relationship between organiza tional aspects of memory and severity of memory are subsidiary interests.

\section{GENERAL HYPOTHESES}

1. It is predicted that amnesic patients will be able to utilize organizational features of stimulus material under the conditions of perception 은. short-term recall and recognition, but will show a deficit in the use of organizational features of 18 
stimulus material to promote retrieval by delayed recall.

2. Head injury patients, while recovering, will approach normal subjects in the differential ability to recall related as opposed to unrelated materials.

3. Head injury patients with the most serious neurological symptoms or the greatest number of neurological signs will demonstrate more impairment of recall for related compared to unrelated stimulus material relative to less severely impaired patients.

\section{EXPERIMENTAL PROCEDURE}

\section{DESCRIPTION AND RATIONALE OF TESTS}

A Memory Scale was constructed that contained both related and unrelated stimulus material designed for the following four conditions of presentation: perception (object naming), immediate recall, delayed recall and recognition.

MEMORY SCALE: CONDITIONS OF PRESENTATION 1. Perception (object naming) Perception was operationally equated with the ability to name pictures (object naming).

2. Immediate recall Immediate recall was measured by the ability to remember items immediately after they were removed from sight (five seconds after the object-naming task had occurred).

3. Delayed recall Delayed recall was measured by the ability to recall objects after approximately five minutes had elapsed. In particular, five minutes after exposure to a stimulus card, one of the cue pictures from that card was shown to the subject and he was required to recall the other pictures that appeared on the card.

4. Recognition Recognition was measured by the ability to select the three pictures on the stimulus card originally presented from among the six pictures on a recognition card.

\section{SUBJECT SELECTION}

The criterion for selection of the head injury group was manifestation of acute head injury requiring hospitalization where the diagnosis was head injury, cerebral concussion, or skull fracture. Since no independent measure of post-traumatic amnesia was readily available other than performance on the Memory Scale, all available head injury cases in the acute phases were included in the sample. ${ }^{2} \mathrm{~A}$ control group of accident victims was also selected. Both the acute head injury cases and the accident controls were obtained serially from several large urban general hospitals. An attempt was made to test both groups within 24 hours after trauma, or as soon after injury as feasible. Whenever possible, in order to test recovery, subjects were retested daily on alternative forms of the Memory Scale for as long as they remained in the hospital.

Forty-seven head injury cases were selected and tested between 21 July 1962 and 30 May 1963. Fortyfour control subjects were also secured during this period. The head injury and accident controls subjects were matched for age, educational level, occupational status, performance on the Ammons Picture Vocabulary Test ${ }^{3}$ and a Picture Similarities Test (this latter test was constructed to measure conceptualization).

\section{RESULTS}

HYPOTHESIS 1: ORGANIZATION OF STIMULUS MATERIAL In assessing the implications of the study, it is important to keep in mind Schilder's (1934) assertions about PTA. He claims that amnesia represents one of the later stages in the recovery of consciousness. In the early stage(s), in addition to the amnesia there is often disorientation and intellectual, cognitive, and perceptual difficulty. Since 17 of the 47 head injury subjects scored on the Ammons Test at the borderline level of intelligence (IQ 79 or below), it is likely that this group of patients were more severely brain damaged and/or were in an earlier stage in the recovery of consciousness. Hence, it is important to consider these patients separately.

${ }^{2}$ However, head injury and control patients who were clearly alcoholic, who had other neurological complications (epilepsy, severe cerebral palsy), or who were clearly emotionally disturbed (psychotic, delirious, severely depressed) or aphasic were excluded from the sample. In addition, only cases between the ages of 15 and 65 were included.

3 The Ammons Picture Vocabulary Test, which measures recognition vocabulary, was employed to control for intelligence for three main reasons. First, the Ammons Test is reported to have a high correlation with the Wechsler Bellevue Scale in an adult population-Ammons, Larson, and Shearn (1950) report a correlation of $0 \cdot 81$. Second, according to Blatt (1959), vocabulary is less affected by brain damage than other measures of intelligence, and recognition vocabulary is less affected than recall vocabulary. Finally, the Ammons Test was selected because it is a brief test and capable of being administered to an ill, bedridden patient. Since it is acknowledged that mildly aphasic patients might do poorly on such a task, aphasics were specifically excluded from the study, although it is possible that a few mild anomics might have been selected. However, Heilman, Safran, and Geschwind (1971) report a very low incidence of aphasia after closed head injury (13 out of 750 cases sampled). Hence, it is felt that aphasia was not a confounding variable in the control of intelligence. 
Table 1 shows that the head injury patients (64\% of the sample) who scored at approximately the normal level on the Ammons Test (IQ 80 or above) generally followed the predictions. When an analysis of variance is applied to these data (Table 1), it is seen that object naming, immediate recall, and recognition of related and unrelated stimulus material do not differ significantly for the head injury and accident control

\section{TABLE 1}

ANALYSIS OF VARIANCE F RATIOS FOR OBJECT NAMING, IMMEDIATE RECALL, DELAYED RECALL AND RECOGNITION FOR THE HEAD INJURY AND CONTROL PATIENTS WITH IQS OF 80 OR ABOVE

\begin{tabular}{lccc}
\hline & $\begin{array}{c}\text { Related } \\
\text { stimulus } \\
\text { material }(R)\end{array}$ & $\begin{array}{c}\text { Unrelated } \\
\text { stimulus } \\
\text { material }(U)\end{array}$ & $\begin{array}{c}\text { Differences } \\
(R-U)\end{array}$ \\
\hline Object naming & $F$ & $F$ & $F$ \\
Immediate recall & $2 \cdot 11$ & 0.65 & 0.30 \\
Delayed recall & $3 \cdot 10$ & 1.58 & 0.01 \\
Recognition & $8.01^{*}$ & 0.24 & $7 \cdot 79^{*}$ \\
& 3.22 & 1.68 & 0.00 \\
\hline
\end{tabular}

* $\mathrm{P}=$ smaller than 0.01 .

groups. However, the $\mathrm{F}$ ratio of 8.01 for delayed recall of related material, compared with unrelated material, is significant at the 0.01 level of significance. Thus, it is concluded that the head injury patients who were presumed to have post-traumatic amnesia exhibited a disturbance in the retrieval of related stimulus material relative to a control group. Cognitive and perceptive abilities were not affected, nor was immediate recall and recognition of related and unrelated stimulus material. Hence, while head injury patients demonstrate adequate ability to deal with coding on the perceptual level and for immediate recall, compared with the control group they seem less able to utilize these codes fully as an aid in delayed recall. However, consistent with Weiskrantz and Warrington's 1970 finding that amnesics do use coding, the deficit involves a reduced capacity to utilize organization rather than a complete failure. However, the fact that recognition is intact suggests that the prime deficit is one of retrieval by recall. The material is retained, but is unavailable for recall. Of interest is the finding that recognition for bothe head injury and control subjects for related material was at approximately the same level as unrelated material.

A second group of head injury patients $\left(36^{\circ} \%\right.$ of the sample) demonstrated poor intellectualo functioning, scoring below the tenth percentiles on the Ammons Test (IQ 79 or below). While they were matched with a low IQ control group they generally did less well on perception and immediate recall, as well as the delayed recalls? task, compared with a control group. ${ }^{4}$ Table $\bar{Z}$ presents an analysis of variables for these data

TABLE 2

ANALYSIS OF VARIANCE F RATIOS FOR OBJECT NAMING, IMMEDIATE RECALL, DELAYED RECALL AND RECOGNITION FOR THE HEAD INJURY AND CONTROL PATIENTS WITH IQS OF 79 OR BELOW

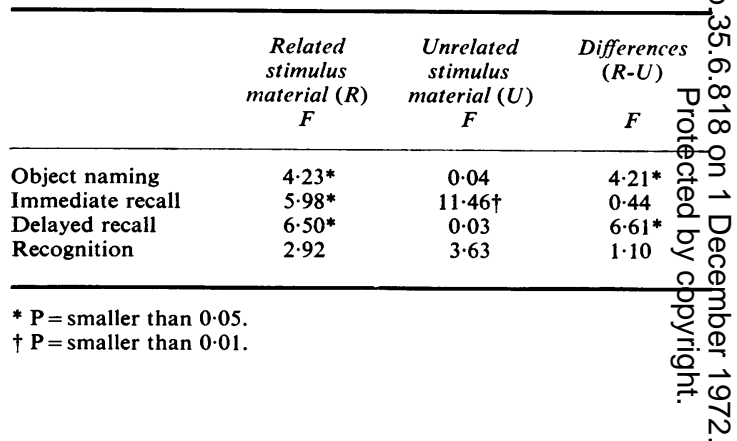

Significant $F$ ratios occur for object naming and immediate and delayed recall of related stimulus material. A wider deficit in the use of organiza tion is also suggested in that both object naming and delayed recall of related (as opposed to un related) stimulus material was also significantly lower for the experimental group compared with the control group.

In spite of the broad amnesic pictures and the difficulty in dealing with organizational features of stimulus material, recognition again remains intact. This finding suggests that amnesia may be more related to retrieval by recall than to recogo nition.

${ }^{4}$ It is possible that an IQ of 79 or below on the Ammons Test for the head injury group may not reflect premorbid intelligence as much å impairment related to the injury. Thus, the two groups may not hav been adequately matched which restricts the interpretations of thestar findings. 
In summary, then, the group of patients with IQ scores of 79 or below exhibited deficiencies that were more typical of a general brain-damaged syndrome than for an amnesic population. For the most part, these patients appeared to be in an early stage after the recovery of consciousness and their performance resembled that of Korsakoff patients (Talland, 1965).

HYPOTHESIS 2: RECOVERY OF MEMORY FUNCTIONS One of the advantages of studying PTA after closed head injury is that the memory disorder is transient and recovery can be observed on a day-to-day basis. The ideal way of studying recovery is to follow amnesia patients from the time of trauma to the point of recovery. This was not always possible. Several alternative methods were devised to study the available data. One method consisted of comparing patients tested soon after injury with patients tested later, while another approach was to follow the same patients over the course of four to six days of consecutive testing.

For the group as a whole, when patients who were first tested soon after injury are compared with those tested later, no definite trends toward recovery were observed on any parts of the Memory Scale (Fig. 1). No recovery trends were observed either on follow-up testing for four, five, or six days (Fig. 2). One severely impaired patient who was subject to study over a period of four months showed considerable improvement in perception and immediate recall soon after injury, but significant improvement in delayed recall for structured stimulus material and recognition took longer. Even after four months he did not consistently reach the level of the control group on the later tests.

The results of other follow-up studies of head injury cases suggest that complete recovery may take several months and that some patients may not completely recover during that period (Reusch, 1944; Denny-Brown, 1945).

HYPOTHESIS 3: SEVERITY It was predicted that head injury patients with the most severe neurological symptoms would show the greatest impairment of delayed recall for related material.

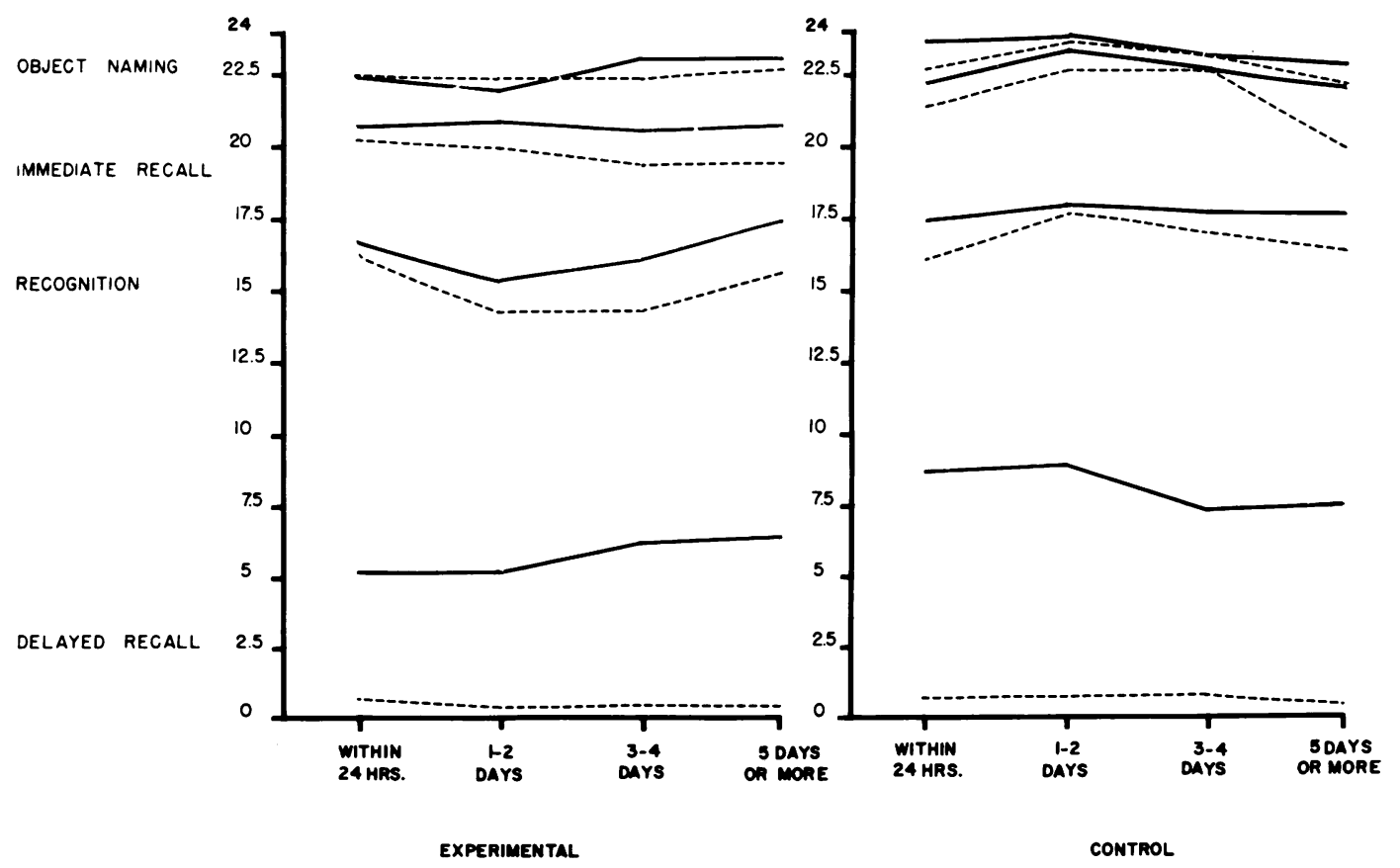

FIG. 1. Mean scores on the memory scale for experimental and control subjects first tested soon after injury and those tested later. 

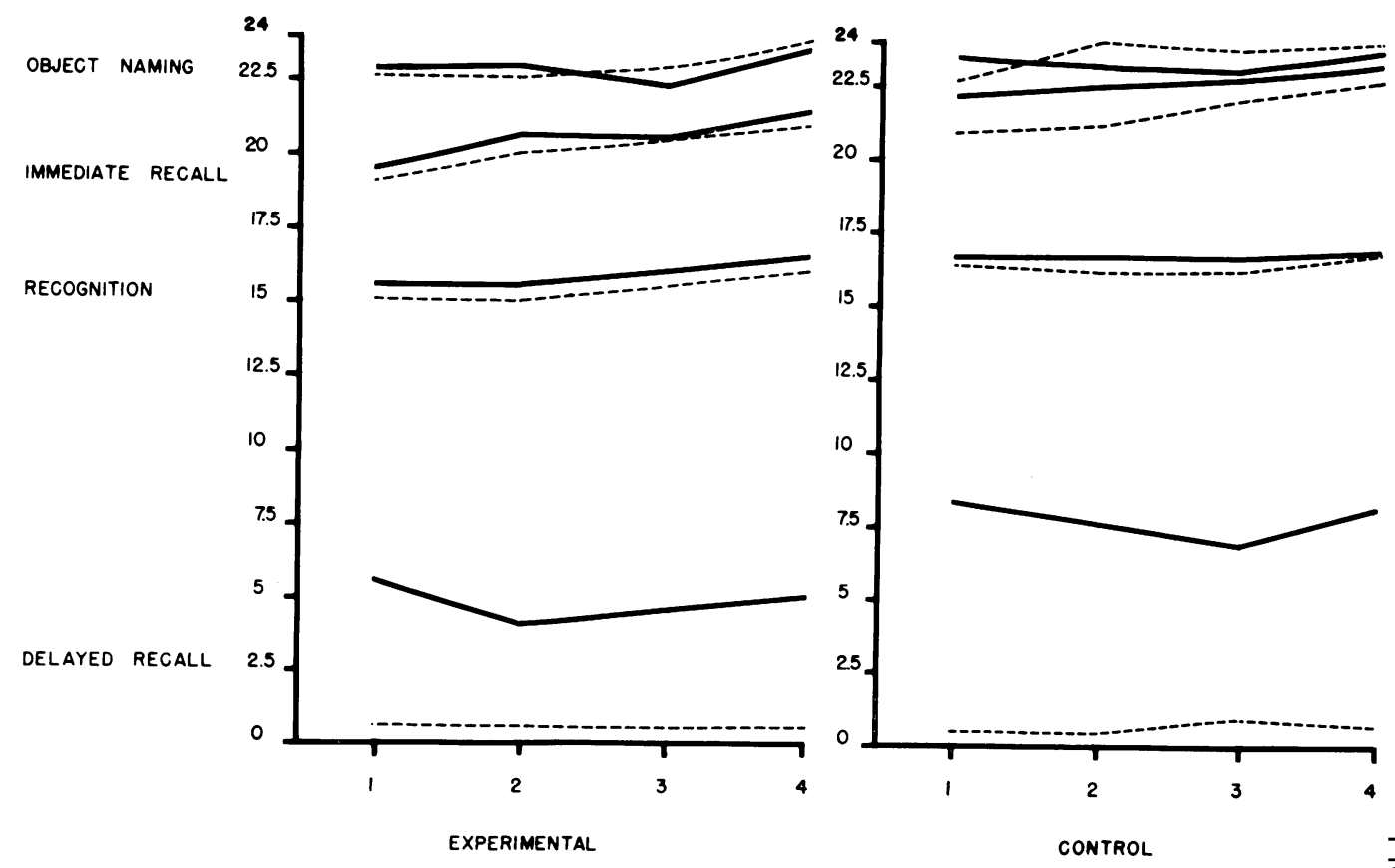

FIG. 2. Mean scores on the memory scale for experimental and control subjects on four consecutive days

Related - - . Unrelated ----.

To assess severity, each neurological symptom was rated on a 0-to-3 scale of severity, and contingency coefficients of correlation were computed between these neurological ratings and delayed recall for related material, as well as for the total memory score on the Memory Scale (all conditions but object naming). In addition, a total weight was obtained which was based on the number of neurological signs. PearsonProduct Moment Correlations were obtained for the overall neurological weight and parts of the Memory Scale, as well as the Ammons and Picture Similarities Tests.

Table 3 presents the contingency coefficients of correlation for the individual neurological symptoms with delayed recall for related material and with the total memory score for the head injury patients. There were no statistically significant correlations. No specific symptoms were associated with delayed recall of related stimulus material or performance on the total Memory Scale.

Table 4 presents Pearson-Product Moment Correlations between the total number of neuro- logical signs and parts of the Memory Scale, well as the Ammons and Picture Similaritte Tests. Again, there are no significant correlatiôn of number of signs with delayed recall scores oN performance on the total Memory Scale. How ever, performance on the Ammons and Pictures Similarities tests was correlated with the number

TABLE 3

CONTINGENCY COEFFICIENTS OF CORRELATION BETWEEN NEUROLOGICAL SYMPTOMS AND PARTS OF MEMORY SCALE FOR HEAD INJURY POPULATION ON FIRST DAY OF TESTINEே

\begin{tabular}{|c|c|c|}
\hline Neurological symptom & $\begin{array}{c}\text { Delayed recall } \\
\text { (related stimulus } \\
\text { material) }\end{array}$ & $\begin{array}{l}\text { Total memor } \\
\text { scores }\end{array}$ \\
\hline $\begin{array}{l}\text { Period of unconsciousness } \\
\text { Period of retrograde amnesia } \\
\text { Period of disorientation } \\
\text { Headache } \\
\text { Lethargy } \\
\text { Abnormal neurological examina- } \\
\quad \text { tion (abnormal reflexes, pupil- } \\
\text { lary responses, bleeding ear) } \\
\text { Positive skull films (fractured } \\
\text { skull) }\end{array}$ & $\begin{array}{l}(+) 0.30 \\
(+) 0 \cdot 14 \\
(-) 0.09 \\
(+) 0.25 \\
(-) 0.17 \\
(-) 0.06 \\
(-) 0.18\end{array}$ & 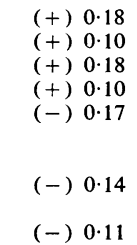 \\
\hline
\end{tabular}


of neurological signs and a similar non-significant trend exists for object naming and immediate recall. Hence, intellectual functioning and deficiencies in immediate recall may be more relevant to the neurological aspects of injury than delayed recall or memory functioning per se. The prediction of a relationship between neurological symptoms and impairment of memory functioning arises from claims by Russell (1959) and others that PTA is the best index of neurological severity. However, in most studies, estimates of PTA are based on clinical evaluation and not on performance on memory tasks. When objective measures of memory functions and ratings of severity are used, no relationship is seen.

\section{TABLE 4}

PEARSON-PRODUCT MOMENT CORRELATIONS BETWEEN INDEX OF SEVERITY OF NEUROLOGICAL SIGNS AND PERFORMANCE ON MEMORY AND AMMONS TESTS ON FIRST DAY OF TESTING FOR HEAD INJURY SUBJECTS

\begin{tabular}{|c|c|c|}
\hline Test scores & Correlation & $\begin{array}{c}\text { Significance } \\
\text { level }\end{array}$ \\
\hline Ammons raw score & -0.32 & $0.05^{*}$ \\
\hline Days since trauma first tested & $+0 \cdot 13$ & NS \\
\hline Picture similarities test & $-0 \cdot 29$ & $0 \cdot 05^{*}$ \\
\hline Total object naming score & $-0 \cdot 17$ & $0 \cdot 05-0 \cdot 10$ \\
\hline Total immediate recall score & $-0 \cdot 27$ & $0 \cdot 05-0 \cdot 10$ \\
\hline Total delayed recall score & -0.03 & NS \\
\hline $\begin{array}{l}\text { Total delayed recall score for related } \\
\text { material }\end{array}$ & $0 \cdot 00$ & NS \\
\hline $\begin{array}{l}\text { Total delayed recall score for un- } \\
\text { related material }\end{array}$ & +0.06 & NS \\
\hline Total recognition score & $-0 \cdot 10$ & NS \\
\hline $\begin{array}{l}\text { Total for related material score on } \\
\text { memory scale }\end{array}$ & -0.21 & NS \\
\hline $\begin{array}{l}\text { Total unrelated score for memory } \\
\text { scale }\end{array}$ & $-0 \cdot 18$ & NS \\
\hline Total score on memory scale & -0.20 & NS \\
\hline
\end{tabular}

* Statistically significant.

\section{SUMMARY}

The present study was concerned with evaluating memory functions after head injury, as well as determining which phases of memory are most impaired. Emphasis was placed on studying delayed recall of related stimulus material, compared with unrelated material. Recovery of memory functions and the relationship between memory functioning and severity of injury were also studied.
Forty-seven acute head injury patients were tested as soon after injury as possible and matched with 44 control subjects (patients with acute trauma, but no head injury). The Ammons Picture Vocabulary Test and a Picture Similarities Test were administered to both groups.

A Memory Scale was constructed to assess perception, immediate recall, delayed recall, and recognition of related and unrelated stimulus material.

Head injury patients with approximately normal intelligence (Ammons IQ 80 or above) performed as follows on the Memory Scale. Retrieval of related stimulus material was impaired, while retrieval of unrelated stimulus material was unimpaired. Perception (object naming), immediate recall, and recognition of related and unrelated material were unimpaired.

The findings with the patients with normal intelligence suggest that, while cognitive and perceptual abilities are not affected by trauma, utilization of organization as an aid in delayed recall of related stimulus material is not as effective in the experimental as in the control group.

Head injury patients with low IQs (79 or below on the Ammons Test) demonstrated impairment of perception and immediate recall, as well as the predicted impairment of delayed recall. These patients appeared to exhibit a generalized cognitive disturbance.

No definite trends toward recovery were observed on any of the memory tests. There was also no relationship between severity of injury and performance on the Memory Scale. However, there was a significant correlation between low performance on the Ammons and Picture Similarities tests and degree of neurological severity. Intellectual and cognitive functioning thus appear to be more closely associated with severity of injury than is memory functioning per se.

\section{REFERENCES}

Ammons, R. B., Larson, W. L., and Shearn, C. (1950). The full-range picture vocabulary test: V. Results for an adult population. Journal of Consulting Psychology, 14, 150-155. Baddeley, A. D., and Warrington, E. K. (1970). Amnesia and the distinction between long- and short-term memory. Journal of Verbal Learning and Verbal Behavior, 9, 176-189.

Blatt, S. J. (1959). Recall and recognition vocabulary. Archives of General Psychiatry, 1, 473-476.

Buerger-Prinz, P. H., and Kaila, M. (1951). On the structure of the amnesic syndrome. In Organization and Pathology of 
Thought, pp. 650-686. Columbia University Press: New York.

Cronholm, B., and Jonsson, I. (1957). Memory functions after cerebral concussion. Acta Chirurgica Scandinavica, 113, 263-271.

Dailey, C. (1956). Psychologic findings five years after head injury. Journal of Clinical Psychology, 12, 349-353.

Denny-Brown, D. (1945). Disability arising from closed head injury. Journal of the American Medical Association, 127, 429-436.

Dixon, K. C. (1962). The amnesia of cerebral concussion. Lancet, 2, 1359-1360.

Fodor, I. E. (1965). Impairment of Memory Functions Following Acute Head Injury. Unpublished Doctoral Dissertation, Boston University.

Heilman, K. M., Safran, A., and Geschwind, N. (1971). Closed head trauma and aphasia. Journal of Neurology, Neurosurgery, and Psychiatry, 34, 265-269.

Ruesch, J. (1944). Intellectual impairment in head injuries. American Journal of Psychiatry, 100, 480-496.
Norman, D. A. (1969). Memory and Attention. Wiley: New York.

Russell, W. R., and Nathan, P. W. (1946). Traumatic amnesia. Brain, 69, 280-300.

Russell, W. R. (1959). Brain, Memory, Learning. Clarendon Press: Oxford.

Schilder, P. (1934). Psychic disturbances after head injuries. American Journal of Psychiatry, 91, 155-188.

Smith, A. (1961). Duration of impaired consciousness as an index of severity in closed head injuries: a review. Diseases $\subseteq$ of the Nervous System, 22, 69-74.

Symonds, C. P. (1937). Mental disorder following head injury. Proceedings of the Royal Society of Medicine, 30, 1081-1094.

Talland, A. G. (1960). Psychological studies of Korsakoff's $\stackrel{\vec{P}}{\oplus}$ psychosis: VI. Memory and learning. Journal of Nervous and Mental Disease, 130, 366-385.

Talland, G. (1965). Deranged Memory. Academic Press: New York.

Weiskrantz, L., and Warrington, E. (1970). A study of for- $\Omega$ getting in amnesic patients. Neuropsychologia, 8, 281-288. 